\title{
NeEds Assessment for Exchange Students IN TAIWAN
}

\author{
Kentei Takaya ${ }^{a}$ \\ Fukuoka Jo Gakuin University
}

\begin{abstract}
With the growing mobility of international students in Asia and the Pacific, Taiwan has become actively involved in promoting international academic exchange. This research investigates the experience of exchange students from the Philippines and mainland China and examines their needs while studying in Taiwan. Qualitative in-depth interviews were conducted with exchange students from the Philippines and mainland China. The findings suggest that while exchange students from the Philippines and mainland China both encountered difficulties during their study in Taiwan, exchange students from the Philippines were inclined to encounter more difficulties compared to those from mainland China due to language difficulties. Based on the findings of this study, suggested support services for future exchange students in Taiwan are outlined to match the needs of students from both Chinese and non-Chinese-speaking backgrounds.
\end{abstract}

Keywords: needs assessment, exchange programme, exchange students, student mobility, international education

\section{Introduction}

The number of international students seeking educational mobility is forecast to increase from 1.8 million in 2000 to 7.2 million in 2025 (Bohm, Meares and Pearce, 2002). Over the past decade, Taiwan has become an attractive destination for study and the number of international students in Taiwan has been increasing steadily. Taiwan has been described as "one of the most highly educationally developed economies in the world" (Guo 2005, p.120), and expanding recruitment of international students is "a way of increasing Taiwan's visibility and its contacts with other countries, and promoting its regional and global influence" (Ma 2013, p.134).

The term 'soft power,' coined by Nye (1990), refers to the ability to attract others and shape their preferences. In 2009, President Ma Ying-Jeou pledged that his administration would send 10,000 Taiwanese students on study or goodwill visits annually as part of his administration's 'soft power diplomacy.' Ma said that by doing so, he also hoped to see 20,000 students coming to Taiwan to study every year, allowing the international community to get to know and support Taiwan through such exchanges (The China Post, 2009).

The term 'exchange student' is sometimes used interchangeably with 'international student' or 'foreign student.' While " 'international student' is a broad term and can be used to refer to different groups of students such as undergraduates, postgraduates, short-term exchange students and so forth" (Wenhua and Zhe 2013, p.400), 'exchange students' typically refer to students who study abroad for a semester or a year (UMAP, 2016), or three to twelve months (Erasmus Programme, 2016).

In 2010, the Taiwanese government lifted the ban on recruiting students from mainland China, and this cross-straitisation of higher education in Taiwan has further increased the number of exchange students in the state. A report in Taipei Times shows that the majority of the international students in Taiwan come from Asian countries: "Southeast Asian nations are the top source of

\footnotetext{
Correspondence can be directed to: takaya@fukujo.ac.jp
} 
expatriate students pursuing formal academic degrees, while those from China form the bulk of exchange students in short-term study programs" (Taipei Times, 2012).

As the number of international students in Taiwan has been increasing, Hwang et. al. (2011) suggest that universities should focus on improving campus support for international students. This paper investigates the experiences of exchange students from the Philippines and mainland China and examines their needs while studying in Taiwan. In order to increase students' level of satisfaction with their international experience, Roberts and Dunworth (2012) argue that service providers for international students need to be more aligned with the students' expectations of service provision. Therefore, to enhance exchange students' experience of studying in Taiwan, and to provide support that matches their needs, it is important to first understand their needs by examining their experiences.

\section{Internationalisation and Globalisation of Higher Education}

Li and Bray (2007) claim that "international mobility of students not only contributes to the internationalization of institutions but also impacts on the outlooks and subsequent careers and lifestyles of the students themselves" (p.793). Knight (1999) defines internationalisation as "the process of integrating an international/intercultural dimension into the teaching, research and service functions of the institution" (p.16). Internationalisation of higher education can also be understood as "a long-term strategic policy for the establishment of overseas links for the purposes of student mobility, staff development and curriculum innovation" (Rubzki 1995, p.422). Further according to Knight (2008), this can be achieved through the following:

(...) international cooperation and development projects; institutional agreements and networks; the international/intercultural dimension of the teaching/learning process, curriculum and research, campus-based extracurricular clubs and activities; mobility of academics through exchange, field work, sabbaticals and consultancy work; recruitment of international students; student exchange programs and semesters abroad; joint/double degree programs; twinning partnerships; and branch campuses. (p.xi)

These views suggest that international students play an important role in the internationalisation of higher education. International student recruitment can "help support a wider 'internationalisation' agenda in terms of developing globally relevant curricula, facilitating student and faculty exchange, and improving campus diversity and fostering cultural understanding" (Woodfield 2010, p.115). International students can also "bring information (social, political, or economic) about their home countries and thus widen the instructor's and the [host] students' perspectives on the world" (Ladd and Ruby 1999, p.363).

Altbach, Reisberg, and Rumbly (2009) see the effects of the global environment as unavoidable for higher education and describe internationalisation as a response to globalisation. Knight (1997) refers to the latter as the "the flow of technology, economy, knowledge, people, values, [and] ideas... across borders" (p.6), and further distinguishes internationalisation and globalisation by claiming that "internationalization is changing the world of education and globalization is changing the world of internationalization" (Knight, 2003, p.30).

With the effect of educational globalisation in Taiwan, English education has been emphasised throughout primary and secondary education (Chang, Wu, Ching, Tang and Xiao, 2011). In addition, Taiwan's higher education institutions have been actively attempting to participate in the globalised world of education by internationalising themselves (Lo, 2009), and as a result, "foreign students, international students, sister schools, and exchange programs are quite common in [Taiwan]" (Chang et al. 2011, p.37). 


\section{Exchange Student Adjustment}

Andrade (2006) argues that universities must become more knowledgeable about the adjustment issues faced by international students and provide appropriate support services. Adjustment refers to the 'fit' between students and the academic environments (Ramsay, Barker and Jones, 1999); it may include issues such as learning style, study habits, educational background, culture and language proficiency (Andrade, 2006). Adjustment can also be seen "as representing a transitional process that unfolds over time as students learn to cope with the exigencies of the university environment" (Al-Sharideh and Goe 1998, p.701).

$\mathrm{Yi}$ et al. (2003) identified five adjustment issues that international students are likely to experience in the United States. These include academic, physical health, financial, vocational, and personal/social issues. Jenkins and Galloway (2009) investigated adjustment problems faced by international and overseas Chinese students studying in Taiwanese universities and found that international students experienced more problems in the area of Chinese language than overseas Chinese students. Chou, Roberts, and Ching (2012) examined issues and dilemmas surrounding international students' experience in Taiwan, and they found that understanding lectures, expressing opinions to teachers, and communicating in Chinese were among the most difficult aspects of studying in Taiwan, followed by making oral presentations, working on group projects, studying in a different educational system, completing assignments on time, and managing their study loads. Further, Hwang, Wang, and Sodanine (2011) investigated factors that influence learning performance of international students in Taiwan and found that adjustment and support are two important factors that assist international students in improving their learning performance. While research has been conducted to explore the adjustment issues faced by international students in Taiwan, no comparative studies have been performed to investigate how these adjustment issues and challenges differ depending on the students' country of origin.

Research on enhancing international students' experience has focused on programmes to help them adjust to the new environment by pairing them with local students. These programmes go by different names depending on the researcher, including peer programme (Abe, Talbot and Geelhoed, 1998), peer-support programme (Andrade, 2006), peer pairing programme (Devlin, 1997), international peer programme (Geelhoed, Abe and Talbot, 2003), S.O.S. (Student for Other Students) program (Stone, 2000), and the buddy project (Campbell, 2012).

Campbell (2012) conducted a 'buddy project' in a university in New Zealand, where students from the host institution became the buddies of newly arrived international students for a semester to help them adjust to the new environment. The findings suggest that the buddy project was beneficial for both the guests and the home students in that it helped each gain practical experience in intercultural communication.

Furnham and Bochner (1982) claim that if students "are introduced into a new society by close, sympathetic host-culture friends, the evidence indicates that they may encounter fewer problems than if they are left to fend for themselves" (p.171). Furthermore, studies conducted by Furnham and Alibhai (1985) in British universities and Kashima and Loh (2006) in Australian universities have found that students can adjust better psychologically if they have personal ties with the locals.

While a number of studies have investigated adjustment in international students, many of these were done in Anglophone countries in the West. As Kondakci et al. (2008) argues, "there is a need to analyze students' experiences in the non-Anglophone and non-traditional destination of foreign students" (p.449).

\section{Context}

The site for investigation of this study was one of the top private universities in Taiwan, with approximately 21,600 undergraduate and 3,800 graduate students. The university has accepted more than 400 exchange students. The study was guided by the following research questions: 
1. What issues and challenges are faced by exchange students from the Philippines?

2. What issues and challenges are faced by exchange students from mainland China?

3. How do exchange students from the Philippines and mainland China compare with regard to the issues and challenges they face?

A convenience sample of eleven (11) exchange students, six from the Philippines (female $n=2$; male $n=4$ ) and five from mainland China (female $n=5$ ) were recruited for this study. The students from the Philippines were all business management majors and the students from mainland China were all English majors. All 11 participants were in their third year of undergraduate study, and were studying in Taiwan for one semester. The host university has a peer-pairing support program called 'babysitters' to support the exchange students' adjustment to Taiwan. In this study, all 11 exchange students were automatically paired with local Taiwanese students who volunteered to be the babysitters.

In order to understand their adjustment issues in Taiwan in great detail, in-depth semistructured interviews were conducted with each of the participants. The interviews were done in English and all participants consented to be interviewed. The interview questions focused on the issues and all the difficulties they had encountered in Taiwan. The same set of interview questions was used for both the Filipino and Chinese exchange students. Although the sample size in this study was small, the number of interviewees was believed to be adequate since, according to Kuzel (1992), in an exploratory study, "five to eight data sources...will often suffice for a homogeneous sample" of informants (p.42). The interview data from this study was expected to provide an insight into aspects that might not have been revealed in studies that mainly used quantitative methods. The interviews were transcribed, and thematic content analysis was performed to collate the information into succinct themes.

\section{The Case of Exchange Students from the Philippines}

\section{Difficulties in Completing Documents Written in Chinese}

One major difficulty encountered by the exchange students from the Philippines was completing a course registration form written in Chinese that they received shortly after arriving in Taiwan. This was expressed by the students in the following comments:

We were surprised to find out we had to ask teachers to sign the course registration documents, and go to the secretary and the documents were all in Chinese!

The course registration documents were written in Chinese and I didn't understand any of the things. I didn't even know where to put my name because it was all in Chinese. So I had to ask someone to help me fill out all my documents.

As the comments above show, the documents written in Chinese made the course registration process very difficult for the exchange students from the Philippines, as they did not have adequate Chinese language skills to be able to complete the forms.

\section{Lack of Specialised Courses in English}

While there was a wide range of courses offered in English at the host university, a lack of specialised courses conducted in English was a problem for the exchange students from the Philippines.

I hope they offer more classes in English. There are a lot, but they are Business English, Basic English, Conversational English, and foreign students already know those, so if we take those, it would be useless and it would be a waste of time, so I hope the university offers more English subjects in the future. 
Since the exchange students from the Philippines already spoke English (considering that English is a working language in the country), it was apparent that they were not interested in taking courses related to learning English language skills but would welcome specialised courses conducted in English.

\section{Language Barrier in Classrooms}

The exchange students were taking classes conducted in English. However, in some classes, the instructors switched from English to Chinese from time to time during lectures, and the exchange students were frustrated whenever this happened.

All our courses are in English, but sometimes the professor translates things in Chinese and if he asks the students, the students reply in Chinese. So there are times when I don't relate to what's happening in the classroom.

The teachers were speaking Chinese and some of the students were speaking Chinese, so sometimes I don't really understand that well. And they know that I can speak some Chinese so they speak to me in Chinese and sometimes I can't really understand what they are saying when they are speaking too fast.

The Filipino students' language-related problems were not limited to situations when teachers spoke Chinese, but also occurred when local students spoke Chinese to them during group discussions.

The way of instruction here is a little different from the Philippines. The classes here encourage a lot of talking in the class, but then, it's kind of hard for me because sometimes the students speak in Chinese and I don't understand.

I think it's difficult to communicate with the people. Because when I speak in English, sometimes they don't understand what I am saying in the discussion. Sometimes they talk to me in Chinese, even though I explain to them that I am from the Philippines. It's hard.

There was an incident in my Global Fashion class. Our group mates were speaking in Chinese and we were speaking in English, and we didn't understand that much, so we were having difficulty just making a group report because both sides were speaking different languages (...).

As these comments show, in courses where English is supposed to be used as the medium of instruction, exchange students from the Philippines became frustrated whenever their instructors and classmates unexpectedly used Chinese during the classes or group work.

\section{Difficulty Adjusting to the Local Learning Style}

Learning behaviour varies across students from different Asian backgrounds (Marambe, Vermunt and Boshuizen, 2012). One exchange student from the Philippines described his difficulty in adjusting to the local learning style as follows:

In the Philippines, we really don't memorise things, so I think that's the biggest obstacle that I faced here, because I'm not used to memorising things. I'm used to reading and analysing and teachers ask us to write a paper, but here, we need to read the book and memorise terms for exams. 
The Chinese way of learning is characterised by the intention to understand and memorise (Kember, 1996), and the learning style in Taiwan follows this tradition by putting emphasis on rote learning. This made for a difficult adjustment for the exchange students from the Philippines.

\title{
Need for Compatible Grading Standards
}

The differences in grading standards between the exchange students' home university in the Philippines and their host university in Taiwan was also pointed out as a concern.

\begin{abstract}
We didn't look through the syllabus. Personally I didn't look that much at the syllabus when it was first given to me, but then when we received the grade for the first time, I was shocked that it was really low. In the Philippines, we have the letter grading system: $A, B+, B, C+, C$, and so on. But here, I think there's just the number system, so it's very unusual for me, and the standard is different. In our school in the Philippines, you get an A if you get a score of 90 and above. An A here is around only 85, and if you get 80, the professor will interpret you as smart, and you are doing good in her class. But in my university, if you get 80 , then you're doing so-so, not very well. So that came as a big surprise to me. So I brought it up to some professors to see if they could adjust the score... we were scared to get 80.
\end{abstract}

From this account, it can be said that the problem regarding what are considered 'good grades' under the two different systems needs to be resolved in order for the exchange students to be assessed fairly.

\section{Lack of Support from the 'Babysitter' System}

The responsibility of 'babysitters' is to help exchange students fit into the academic and social environment in Taiwan. However, the exchange students complained that they did not get any help from their 'babysitters' when they needed help. One student commented as follows:

The babysitters are not helpful at all (...) I was asking her to help me find the department during the first week, and she just gave me a map of the campus. So we just found our own way. I didn't see her at all. She just added me on the Facebook and that's all.

While some babysitters helped the exchange students a little in the beginning, the exchange students expected that their babysitters would help them more. Consider the following comment:

I think the babysitter could have done some more for us. He just left us. Like on the first day he just told us some things to do and that's it and I never saw him again.

Lack of help from and contact with babysitters can be especially serious when exchange students become ill during their study at the host institution. One student described how much he needed help from his babysitter when he became ill:

I got sick and I found it difficult to find a clinic here. I have insurance, but we don't know how to use it, because I don't know how it works, and I can't really ask how it works because I can't understand what they say to me. I have a babysitter, but he doesn't really help me.

From these comments, it can be said that babysitters for exchange students should be people who will be available and able to support the exchange students for their entire stay in Taiwan. As exemplified in the comments above, a smooth adjustment in the country can be played in part by a successful babysitter programme. 


\section{The Case of Exchange Students from Mainland China}

Analysis of the interview data from the exchange students from mainland China shows that for the most part, they encountered different kinds of difficulties than those by the exchange students from the Philippines.

\section{Difficulties Choosing the Right Courses}

For many exchange students from mainland China, it is crucial for them to carefully select their courses in Taiwan in order for those courses to be recognised for credits by their home university. This, according to some exchange students from mainland China, was a difficult process.

My school wants me to take the similar courses in order for the credits to be recognised back home. It was difficult to choose courses because we need to choose the courses according to the courses we need to take at our school.

One reason why this was a difficult process was because the exchange students found that the course descriptions at their host university in Taiwan were not detailed enough for them to judge the compatibility of the courses. A following student reflected on this in the following comment:

A more detailed course description may be helpful. I had a hard time selecting courses because the courses I take in this university must match with the courses at my home university in terms of course name and content, in order to be considered as credits. But some of the courses have different names, and while it would be all right as long as the course has similar content, it's hard to tell by reading the course descriptions, as they are so vague. Our school is very strict.

Such comments suggest that the need for a more detailed description of courses in the receiving country to accommodate the needs of the incoming students (from China), this will also avoid confusion in terms of course credits procedures in the future.

\section{Difficulty Adjusting to the Local Teaching Style}

The exchange students from mainland China found the teaching style in Taiwan quite different from that of China, and they had difficulties adjusting.

The way class is organised here is very different from what I have experienced. The classes in my university in China are like, teachers teach and students just sit there and listen, and we don't have much interaction. But classes here pay more attention to group work, which is very different, and we are not quite used to this way.

Most of the classes here have discussions but in China we don't have much discussion. In China we focus more on textbooks.

I think the teaching is quite different (...) In my university, we have group work but not that much. I was not very well adjusted to the educational environment here, but I gradually got used to it. Group work was a challenge.

As these comments show, it took some time for the exchange students from mainland China to get used to an educational environment where there is much discussion and group work. 


\section{Lack of Support from the 'Babysitter' System}

Just like the exchange students from the Philippines, mainland Chinese exchange students also voiced concerns about the lack of help and support from their local student buddies, or 'babysitters.' The following comments show how little their buddies helped them:

My buddy helped me only on the first day to show me where to buy things and get the transportation pass. That's all. She is only a Freshman, so she can't help us much.

At first my buddy gave me some information on how to register for courses, but she is busy now so there's no time for her to help me. Especially because she is a Freshman.

My buddy is a Freshman, and I am a little confused about that. She is quite nice, but when we ask some questions, she sometimes is not sure about it because she is a Freshman. It would be more practical for some Juniors to help us.

The buddy program doesn't make much sense. They helped us at the beginning of the semester when we first came here, but we didn't see each other after two or three weeks. My buddy is a senior student but the school should provide a buddy with the same year as us so that we can take classes together and they could help us more.

It can be seen from these comments that one reason why the local babysitter-buddies were not so helpful was due to the fact that they were freshmen, and the babysitters themselves were busy trying to adjust to life as university students. The fact that most of the babysitters were freshmen created a gap between the needs of the exchange students and the ability of the babysitters to help the exchange students.

\section{Discussion}

The comparative analysis of the issues and challenges faced by the exchange students from the Philippines and mainland China reveals that both groups, to a certain extent, faced similar difficulties during their study in Taiwan. However, there were also some group-specific issues and challenges that were faced by the exchange students. Based on the findings of the study, this section outlines ways in which support services for future exchange students in Taiwan can be improved to help exchange students from both Chinese and non-Chinese-speaking backgrounds.

\section{Instructors Should Create an English-Friendly Classroom Environment}

The exchange students from the Philippines commented that some of their instructors' tendency to switch to Chinese from time to time during lectures caused them frustration, and they were unable to follow the lecture when such a language switch occurred. The exchange students from the Philippines also had problems communicating with the local Taiwanese students due to the limited English proficiency of the local students. While the issues related to exchange students' difficulty in following lectures and communicating with classmates are consistent with previous research (e.g., Jenkins and Galloway, 2009; Chou, Roberts and Ching, 2012), the findings from this study offer insight into how such problems can occur so easily in the classroom. To minimise the problems related to instructors' occasional use of Chinese during lectures, instructors should observe to speak English at all times during lectures where exchange students from non-Chinese-speaking backgrounds are present.

According to Liu and Dai (2012) "the English proficiency of the teachers and students of a university indicates the degree and potential possibility of the internationalization of the university" (p.62). Teaching in English requires instructors to have high English proficiency and that "reasonable proficiency in English is prerequisite for the courses offered in English" (Liu and Dai 2012, p.62). 
Therefore, instructors who opt in to offer courses in English must at least be reasonably fluent in English and be capable of conducting lessons in English without switching to Chinese. In addition, when conducting group work and assigning group reports in class, instructors could try to match exchange students from non-Chinese-speaking backgrounds (e.g., the Philippines) with Taiwanese students who have a good command of English. This may further minimise the exchange students' language barrier in the classroom.

\section{Forms and Documents Should Have an English or Bilingual Version}

The exchange students from the Philippines in this study encountered great difficulties in completing their course registration forms, which were entirely in Chinese, and had to ask for help to complete them. While language problems of international students found in previous studies show their challenges in understanding lectures and communicating with classmates (e.g., Jenkins and Galloway, 2009; Chou, Roberts and Ching, 2012), the language problems associated with their completion of forms and documents (e.g., course registration forms) have not been addressed. Therefore, this finding sheds new light on matters related to their language issues. To avoid exchange students from experiencing this kind of problem, forms and documents, such as course registration forms, should have English versions or bilingual versions (English and Chinese) to accommodate exchange students in Taiwan who do not speak Chinese.

\section{Repertoire of Specialised Courses Taught in English Should be Expanded}

While there are many courses in English available for exchange students to take, those courses tend to be EFL (i.e English as Foreign Language) courses, and the exchange students from the Philippines are usually not interested in taking such courses given their high level of proficiency in the language. This issue has not been addressed in previous studies on exchange programmes in non-Anglophone countries, and it is of crucial importance to expand the repertoire of specialised courses offered in English to accommodate exchange students who already speak or are competent in English.

\section{Grade Conversion System Should be Developed}

The exchange students from the Philippines expressed great concerns about the different grading standards between their host and home institutions. The findings reveal that there are crossinstitutional differences in what constitutes 'good grades,' and that a grade conversion system between institutions should be developed to translate grades obtained in the host institution to the grading standards of the home institution. For example, the grade of ' 86 and above' would be considered an ' $A$ ' in Taiwan, while it would be equivalent to a ' $B$ ' in the Philippines. International students have a tendency to expect that they perform just as well as or better than how they performed in their home country (Chen, 1999; Mori, 2000; Pederson, 1991). However, without a fair grade conversion system, their seemingly excellent academic performance at the host institution may be interpreted as poor at their home institution. Just like the credit transfer systems, e.g., the European Credit Transfer and Accumulation Systems (ECTS) and the UMAP Credit Transfer System (UCTS), where credits are calculated and transferred between host and home institutions, grade conversion systems that appropriately translate and convert grades between institutions requires development for future exchange programmes.

\section{Detailed Course Descriptions Should be Provided}

One major difficulty faced by the exchange students from mainland China was related to the course descriptions offered at the host institution. Exchange students must select courses carefully to ensure that the courses they take at the host institution will be counted toward their degree at their home institution. In this study, exchange students from mainland China expressed concern over 
the fact that the course descriptions at the host institution did not include enough detail for them to tell whether or not those courses would be accepted for credit by their home institution. Such a problem has not been mentioned in previous studies on exchange students in Taiwan.

Liu and Dai (2012) argue that "(i)nternationalization of the curriculum in a university cannot be rendered possible without internationalization of the instructors" (p.61). In order to help exchange students to more easily determine the compatibility between the courses at the host institution and the requirements set by their home institution, detailed syllabi for courses open to exchange students must be provided by instructors, and the instructors should be fully aware of such needs.

\section{Information on the Academic Practices of the Host Institution Should be Included in the Orientation Programme}

In this study, exchange students from both the Philippines and mainland China reported that they found it challenging to adjust to the academic environment in Taiwan. Similar to the finding from a study by Chou, Roberts and Ching (2012), which found that international students find it challenging to engage in group projects, the exchange students from mainland China reported that they found it demanding when they experienced group work and group discussions in Taiwan. The exchange students from the Philippines, on the other hand, encountered difficulties when they discovered that the examinations at the host institution emphasised rote-learning skills. To help exchange students adjust to the teaching and learning styles of Taiwan more smoothly, an orientation programme for exchange students before or after they arrive in Taiwan should include some information on the differences between the academic environment in Taiwan and that of their home institutions.

\section{'Babysitter' Buddy Should Have Frequent Contact with Exchange Students}

Unlike previous studies showing that peer-pairing buddy programmes for international students are in fact beneficial (e.g., Furnham and Alibhai, 1985; Kashima and Loh, 2006; Campbell, 2012), the exchange students from both countries in this study were frustrated over the lack of contact and support from their 'babysitter' buddies. Based on the findings from this study, it is recommended that institutions set certain conditions for local students who want to serve as babysitter-buddies for exchange students. For example, babysitter-buddies should agree to have frequent contact with the exchange students and must agree to look after the exchange students until the end of their study. The babysitter-buddies should also be, if possible, at the same year level and major in the same academic field as the exchange students, so that they can meet more often and provide more appropriate support.

\section{Conclusion}

The voices of the exchange students are valuable for understanding their needs while studying in Taiwan. In this study, the issues and challenges faced by exchange students from the Philippines and mainland China in Taiwan were identified using the qualitative research method. Major issues reported by the exchange students from the Philippines included difficulties in completing forms and documents written in Chinese, lack of specialised courses in English, the language barrier in the classroom, difficulty adjusting to the local academic environment where rote-learning is emphasised, the need for compatible grading standards, and a lack of support from their babysitter-buddies. In contrast, the issues reported by the exchange students from mainland China included difficulty in choosing the right courses, difficulty adjusting to a local academic environment that included discussion activities during lectures, and the lack of support from their babysitter-buddies. These findings suggest that while exchange students from the Philippines and mainland China both encountered difficulties during their study in Taiwan, exchange students from the Philippines who do 
not speak Chinese have a tendency to encounter more difficulties compared to those from mainland China due to the language barrier they face.

As exchange students' "perspectives of their experiences can impact future enrollment trends" (Lee, 2010, p.68), appropriate information, services, and programs are vital in helping exchange students have positive experiences (Carr, McKay and Rugimbana, 1999). Moreover, to achieve internationalisation of higher education, it is crucial that local administrators, teaching staff, and students work together to provide support services that actually meet the needs of exchange students.

\section{References}

Abe, J., Talbot, D.M., and Geelhoed, R.J. (1998). Effects of a peer program on international student adjustment. Journal of College Student Development, 39(6), pp. 539-547.

Al-Sharideh, K.A., and Goe, W.R. (1998). Ethnic communities within the university: An examination of factors influencing the personal adjustment of international students. Research in Higher Education, 39(6), pp. 699-725.

Altbach, P., Reisberg, L., and Rumbley, L. (2009). Trends in Global Higher Education: Tracking an academic revolution. Paris: UNESCO.

Andrade, M.S. (2006). International students in English-speaking universities: Adjustment factors. Journal of Research in International Education, 5(2), pp. 131-154.

Bohm, A., Meares, D., and Pearce, D. (2002). Global Student Mobility 2025: Forecast of the global demand for international higher education. Sydney: IDP Education.

Campbell, N. (2012). Promoting intercultural contact on campus: A project to connect and engage international and host students. Journal of Studies in International Education, 16(3), pp. 205-227.

Carr, SC, McKay, D., and Rugimbana, R. (1999). Managing Australia's aid- and self-funded international students. The International Journal of Educational Management, 13(4), pp. 167-172.

Chang, D.F., Wu, C.T., Ching, G., Tang, C.W., and Xiao, L. (2011). Globalization and higher education in Taiwan. In P. Pachura (Ed.), New Knowledge in a New Era of Globalization. Croatia: InTech, pp. 35-48.

Chen, C.P. (1999). Common stressors among international college students: Research and counseling implications. Journal of College Counseling, 2(1), pp. 49-65.

Chou, C.P., Roberts, A., and Ching, G. (2012). A study on the international students' perception and norms in Taiwan. International Journal of Research Studies in Education, 1(2), pp. 71-84.

Devlin, M. (1997). A description and evaluation of a pilot peer pairing program for international and local students. Journal of Australia and New Zealand Student Services Association, 9, pp. 70-77.

Erasmus Programme. (2016). The Erasmus. Available at http://www.erasmusprogramme.com/ the_erasmus.php [Accessed 15 January 2016].

Furnham, A., and Alibhai, N. (1985). The friendship networks of foreign students: Replication and extension of the functional model. International Journal of Psychology, 20(3-4), pp. 709-722.

Furnham, A., and Bochner, S. (1982). Social difficulty in a foreign culture: An empirical analysis of culture shock. In S. Boshner (Ed.), Cultures in contact: Studies in cross-cultural interaction. Oxford: Pergamon, pp. 161-198.

Geelhoed, R.J., Abe, J., and Talbot, D.M. (2003). A qualitative investigation of U.S. students' experience in an international peer program. Journal of College Student Development, 44(1), pp. 5-17.

Guo, Y. (2005). Asia's educational edge: Current achievements in Japan, Korea, Taiwan, China, and India. Lanham, MD: Lexington Books.

Hwang, K., Wang, M.K., and Sodanine, S. (2011). The effects of stressors, living support, and adjustment on learning performance of international students in Taiwan. Social Behavior and Personality, 39(3), pp. 333-344. 
Jenkins, J., and Galloway, F. (2009). The adjustment problems faced by international and overseas Chinese students studying in Taiwan universities: a comparison of student and faculty/staff perceptions. Asia Pacific Education Review, 10(2), pp. 159-168.

Kashima, E.S., and Loh, E. (2006). International students' acculturation: Effects of international, conational, and local ties and need for closure. International Journal of Intercultural Relations, 30(4), pp. 471-485.

Kember, D. (1996). The intention to both memorise and understand: Another approach to learning? Higher Education, 31(3), pp. 341-254.

Knight, J. (1997). Internationalisation of higher education: A conceptual framework. In J. Knight and H. d. Wit (Eds.), Internationalization of Higher Education in Asia Pacific countries. Amsterdam: European Association for International Education, pp. 5-19.

Knight, J. (1999). Internationalization of higher education. In J. Knight and H. d. Wit (Eds.), Quality and Internationalization in Higher Education. Paris: OECD, pp. 13-23.

Knight, J. (2003). Higher education and trade agreements: What are the policy implications? In G. Breton and M. Lambert (Eds.), Universities and Globalization: Private linkages, public trust. Paris: UNESCO Publishing, pp. 81-106.

Knight, J. (2008). Higher Education in Turmoil: The changing world of internationalization. Rotterdam: Sense Publishers.

Kondakci, Y., Van den Broeck, H., \& Yildirim, A. (2008). The challenges of internationalization from foreign and local students' perspectives: The case of management school. Asia Pacific Education Review, 9(4), pp. 448-463.

Kuzel, A. (1992). Sampling in qualitative inquiry. In B. Crabtree and W. Miller (Eds.), Doing Qualitative Research. Newbury Park, CA: Sage, pp. 31-44.

Ladd, P.D., and Ruby, R. (1999). Learning style and adjustment issues of international students. Journal of Education for Business, 74(6), pp. 363-367.

Lee, J. (2010). International students' experiences and attitudes at a US host institution: Self-reports and future recommendations. Journal of Research in International Education, 9(1), pp. 66-84.

Li, M. and Bray, M. (2007). Cross-border flows of students for higher education: Push-pull factors and motivations of mainland Chinese students in Hong Kong and Macau. Higher Education, 53(6), pp. 791-818.

Liu, J., and Dai, Z.X. (2012). On the internationalization of higher education institutions in China. Higher Education Studies, 2(1), pp. 60-64.

Lo, Y.W. (2009). Reflections on internationalisation of higher education in Taiwan: perspectives and prospects. Higher Education, 58(6), pp. 733-745.

Ma, S. (2013). The development of international student recruitment policies in Taiwan: A 60-year trajectory. Journal of Studies in International Education, 18(2), pp. 120-140.

Marambe, K., Vermunt, J., and Boshuizen, H. (2012). A cross-cultural comparison of student learning patterns in higher education. Higher Education, 64(3), pp. 299-316.

Mori, S. (2000). Addressing the mental health concerns of international students. Journal of Counseling and Development, 78(1), pp. 137-144.

Nye, J. (1990). Bound to lead: The changing nature of American power. New York: Basic Books.

Pederson, P.B. (1991). Counseling international students. The Counseling Psychologist, 19(1), pp. 10-58.

Ramsay, S., Barker, M., and Jones, E. (1999). Academic adjustment and learning process: A comparison of international and local students in first-year university. Higher Education Research and Development, 18(1), pp. 129-144.

Roberts, P. and Dunworth, K. (2012). Staff and student perceptions of support services for international students in higher education: A case study. Journal of Higher Education Policy and Management, 34(5), pp. 517-528.

Rubzki, R.E.J. (1995). The application of a strategic management model to the internationalization of higher education institutions. Higher Education, 29(4), pp. 421-441. 
Stone, C. (2000). The S.O.S. program (Student for Other Students): A student mentor program. Journal of the Australian and New Zealand Student Services Association, 16, pp. 55-74.

Taipei Times. (2012). Foreign Student Numbers Almost Double Since 2007. Available at http://www. taipeitimes.com/News/taiwan/archives/2012/01/22/2003523838 [Accessed 8 November 2014].

The China Post. (2009, October 9). Ma Pledges to Push 'Soft Power Diplomacy'. Available at http://m. chinapost.com.tw/taiwan/2009/10/09/227875/Ma-pledges.htm [Accessed 10 February 2015].

UMAP. (2016). University Mobility in Asia and the Pacific. Available at http://www.umap.org/about. html [Accessed 15 January 2016].

Wenhua, H. and Zhe, Z. (2013). International students' adjustment problems at university: A critical literature review. Academic Research International, 4(2), pp. 400-406.

Woodfield, S. (2010). Key trends and emerging issues in international student mobility (ISM). In F. Maringe \& N. Foskett (Eds.), Globalization and Internationalization in Higher Education: Theoretical, strategic and management perspectives. London: Continuum, pp. 109-123.

Yi, J.K., Lin, J.C.G., and Kishimoto, Y. (2003). Utilization of counseling services by international students. Journal of Instructional Psychology, 30(4), pp. 333-342. 
